\title{
Independent inactivation of arginine decarboxylase genes by nonsense and missense mutations led to pseudogene formation in Chlamydia trachomatis serovar L2 and D strains
} Teresa N Giles ${ }^{1}$, Derek J Fisher ${ }^{2}$ and David E Graham*1,3

Address: ${ }^{1}$ Department of Chemistry and Biochemistry, The University of Texas at Austin, Austin, TX 78712, USA, ${ }^{2}$ Department of Microbiology and Immunology, Uniformed Services University of the Health Sciences, Bethesda, MD 20814, USA and ${ }^{3}$ Institute for Cellular and Molecular Biology, The University of Texas at Austin, Austin, TX 78712, USA

Email: Teresa N Giles - tneelima@mail.utexas.edu; Derek J Fisher - dfisher@usuhs.mil; David E Graham* - degraham@mail.utexas.edu

* Corresponding author

Published: 16 July 2009

BMC Evolutionary Biology 2009, 9:166 doi:10.1186/147/-2148-9-166
Received: 18 March 2009

Accepted: 16 July 2009

This article is available from: http://www.biomedcentral.com/147/-2/48/9//66

(C) 2009 Giles et al; licensee BioMed Central Ltd.

This is an Open Access article distributed under the terms of the Creative Commons Attribution License (http://creativecommons.org/licenses/by/2.0), which permits unrestricted use, distribution, and reproduction in any medium, provided the original work is properly cited.

\begin{abstract}
Background: Chlamydia have reduced genomes that reflect their obligately parasitic lifestyle. Despite their different tissue tropisms, chlamydial strains share a large number of common genes and have few recognized pseudogenes, indicating genomic stability. All of the Chlamydiaceae have homologs of the aax $A B C$ gene cluster that encodes a functional arginine:agmatine exchange system in Chlamydia (Chlamydophila)pneumoniae. However, Chlamydia trachomatis serovar $L 2$ strains have a nonsense mutation in their aaxB genes, and $C$. trachomatis serovar $A$ and $B$ strains have frameshift mutations in their aax $C$ homologs, suggesting that relaxed selection may have enabled the evolution of aax pseudogenes. Biochemical experiments were performed to determine whether the $\operatorname{aax} A B C$ genes from $C$. trachomatis strains were transcribed, and mutagenesis was used to identify nucleotide substitutions that prevent protein maturation and activity. Molecular evolution techniques were applied to determine the relaxation of selection and the scope of aax gene inactivation in the Chlamydiales.

Results: The aaxABC genes were co-transcribed in C. trachomatis L2/434, during the mid-late stage of cellular infection. However, a stop codon in the aaxB gene from this strain prevented the heterologous production of an active pyruvoyl-dependent arginine decarboxylase. Replacing that ochre codon with its ancestral tryptophan codon rescued the activity of this self-cleaving enzyme. The aaxB gene from $C$. trachomatis D/UW-3 was heterologously expressed as a proenzyme that failed to cleave and form the catalytic pyruvoyl cofactor. This inactive protein could be rescued by replacing the arginine- 115 codon with an ancestral glycine codon. The aax $C$ gene from the D/UW-3 strain encoded an active arginine:agmatine antiporter protein, while the L2/434 homolog was unexpectedly inactive. Yet the frequencies of nonsynonymous versus synonymous nucleotide substitutions show no signs of relaxed selection, consistent with the recent inactivation of these genes.

Conclusion: The ancestor of the Chlamydiaceae had a functional arginine:agmatine exchange system that is decaying through independent, parallel processes in the $C$. trachomatis lineage. Differences in arginine metabolism among Chlamydiaceae species may be partly associated with their tissue tropism, possibly due to the protection conferred by a functional arginine-agmatine exchange system against host nitric oxide production and innate immunity. The independent loss of $A a x B$ activity in all sequenced $C$. trachomatis strains indicates continual gene inactivation and illustrates the difficulty of recognizing recent bacterial pseudogenes from sequence comparison, transcriptional profiling or the analysis of nucleotide substitution rates.
\end{abstract}




\section{Background}

Members of the Chlamydiaceae family grow inside host cells, when infectious elementary bodies (EBs) differentiate into replicative reticulate bodies (RBs). Worldwide, Chlamydia trachomatis serovars A-C are responsible for millions of cases of conjunctivitis and trachoma [1]. Genital infections by C. trachomatis serovars D-K cause the most commonly reported bacterial sexually transmitted disease [2]. C. trachomatis lymphogranuloma venereum serovars L1-L3 are invasive strains that can disseminate to lymph nodes and cause chronic inflammation. Chlamydia (Chlamydophila)pneumoniae causes $10 \%$ of pneumonia cases each year, and most adults are seropositive for $C$. pneumoniae antigens [3]. Despite differences in tissue tropism and virulence, these chlamydiae share a significant portion of their genomes, including about 711 coding DNA sequences (CDS) [4,5].

The Chlamydiaceae diverged from a non-pathogenic ancestor about 700 mya [5]. Intracellular bacterial pathogens such as Rickettsia and Chlamydia have undergone reductive evolution, as reduced purifying selection and a cascading loss of DNA repair genes led to gene inactivation and genome contraction [6]. While rickettsial genomes have a high number of split genes, a high proportion of noncoding DNA, and a low $\mathrm{G}+\mathrm{C}$ nucleotide composition ( $30 \%)$ [7], chlamydial genomes have few recognized pseudogenes, high coding densities ( $90 \%)$ and moderate $\mathrm{G}+\mathrm{C}$ nucleotide compositions ( $40 \%)$ [8]. Despite the dramatic effects of gene loss, it has been difficult to determine the mode of reductive evolution from the snapshots provided by modern genome sequences. The chlamydial genomes are only half as large as the Parachlamydia sp. UWE25 genome, so both gene acquisition and gene loss have distinguished these lineages [5].

A comparison between genome sequences from C. trachomatis serovars A and D identified only 18 significant deletions in either strain, producing eight pseudogenes (interrupted open reading frames) in serovar A [9]. Another comparison between genome sequences from L2 and serovar A/D strains of C. trachomatis identified 15 pseudogenes in L2 strains [10]. Due to the relatively low number of chlamydial pseudogenes $(<2 \%$ of CDS) and the conservation of chlamydial genome size (1.0 to 1.2 $\mathrm{Mbp}$ ), these bacteria are believed to have undergone reductive evolution, arriving at a stable genome structure. However, this model discounts gene transfer to the Chlamydiales, positive selection for antigenic proteins, and thousands of nonsynonymous amino acid substitutions that have occurred among the strains [9,11-13]. Single nucleotide polymorphisms account for much of the diversity among C. trachomatis serovars [12]. Deciphering the differences in their genetic content will provide important clues to understand tissue tropism and subsequent disease.
Most inactivated, or nonfunctionalized pseudogenes are recognized in genome sequences by the presence of nonsense mutations or indels that substantially truncate CDS compared with homologous sequences. However, these mutations occur less frequently than missense mutations, which can have either minimal or catastrophic effects on protein folding and function [14]. Inactivating substitutions are particularly difficult to identify, since these genes can still be transcribed (and even translated): it is challenging to predict and prove their lack of activity [15]. Even some genes with gross mutations can still be transcribed, leading to a broader definition of pseudogenes that may include many unrecognized elements [16]. In this article, we describe the independent inactivation of two arginine decarboxylase orthologs from Chlamydia trachomatis strains, showing that gene loss continues in these pathogens, and illustrating the challenges of identifying recently nonfunctionalized genes.

We previously identified three genes from C. pneumoniae that comprise an arginine:agmatine exchange system (AAX). The aaxA gene encodes an outer-membrane porin protein that stimulates the activity of this system [17]. The aax $B$ gene encodes an arginine decarboxylase proenzyme that self-cleaves at $\operatorname{Ser}^{53}$ to produce a small $\beta$-subunit and a larger $\alpha$-subunit with a pyruvoyl cofactor that is essential for catalytic activity [18]. Finally, the aaxC gene encodes a cytoplasmic-membrane arginine:agmatine antiporter [17]. Together, these proteins catalyze the import of Larginine, the decarboxylation of arginine to produce agmatine, and the export of agmatine from the cell. All chlamydial genome sequences contain orthologs of the aax $A B C$ genes, which were apparently acquired by the chlamydial ancestor through horizontal gene transfer. Both the C. pneumoniae and C. trachomatis strains require exogenous arginine for growth, and their genomes lack arginine biosynthesis genes $[19,20]$. Chlamydial genomes contain artJ and $g \ln P Q$ genes encoding a putative $\mathrm{ABC}$ type arginine transporter, which is controlled by the ArgR transcriptional regulator in some species [21]. Therefore the AAX system is probably not used to acquire proteinogenic amino acids. Instead, this system could have several possible functions: it could raise the intracellular $\mathrm{pH}$ to resist acidification, produce agmatine - inhibiting host cell polyamine biosynthesis, or inhibit nitric oxide synthesis by host cells [17].

Global microarray analysis indicated that C. pneumoniae aax genes are transcribed late in the developmental cycle [22]. Similarly, C. trachomatis serovar L2/434 cells transcribe the aaxA and aaxB genes beginning 18 hours post infection, shortly before RBs begin to differentiate into EBs [23]. The AaxA protein is incorporated in the outer membrane in EBs from L2/434 cells [24]. Transcriptional profiles from C. trachomatis D/UW-3 cells also identified the highest levels of $a a x B$ and $a a x C$ transcripts at 16-40 
hours post infection [25]. In this report, we confirm the late expression of the $a a x A, a a x B$ and $a a x C$ genes in $\mathrm{L} 2 / 434$ cells and demonstrate that the three genes are co-transcribed, using RT-PCR. However, the C. trachomatis L2/ $434 a a x B$ gene contains an ochre terminator in place of the tryptophan codon 128 found in other chlamydial orthologs (Figure 1) [10]. The resulting L2/434 protein is predicted to be truncated at amino acid 127, compared to the full 195 amino acids found in the homologous proteins. In contrast, the $\mathrm{D} / \mathrm{UW}-3$ a $a x B$ gene is predicted to express a full-length protein that differs in only three positions from the L2/434 homolog.

To determine whether the C. trachomatis L2/434 and D/ UW-3 strains encode functional AaxB arginine decarboxylases, we cloned both a axB genes in $E$. coli and determined heterologous expression using immunoblotting and activity assays. Neither gene produced a functional arginine decarboxylase in E. coli; however, site-directed mutagenesis experiments showed that AaxB from L2/434 could be rescued by an $\mathrm{X}^{128} \mathrm{~W}$ replacement, and AaxB from D/UW3 could be rescued by an $\mathrm{R}^{115} \mathrm{G}$ replacement. Multiple frameshift mutations in aaxC genes from C. trachomatis A/ Har-13 and B/Jali are predicted to inactivate those genes [10]. E. coli cells expressing AaxC demonstrated arginine uptake activity of the D/UW-3 AaxC, but not the L2/434 AaxC proteins. Therefore the AAX system appears to be undergoing inactivation in parallel among the C. trachomatis strains. Transcription of these nonfunctional genes suggests that bioinformatic analysis underestimates the number of inactive genes in organisms undergoing reductive evolution. Neither a comparison of $d_{N} / d_{S}$ values nor amino acid substitution analysis was sufficiently sensitive or specific to detect recent gene inactivation by missense mutations.

1

C. pneumoniae

C. muridarum

C. trachomatis $\mathrm{L} 2$

C. trachomatis D

C. trachomatis $B$

C. trachomatis A

Ct ancestor

MAYGTRYPTLAFHTGGIGESDDGMP PQPFETFCYDSALLQAKIENFNIVPYTSVLPKELFGNIVP

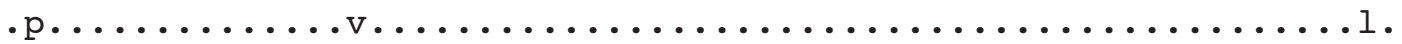

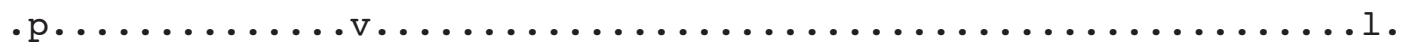

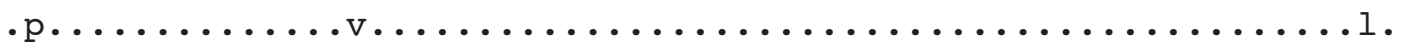

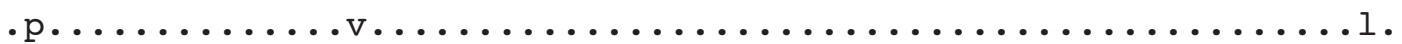

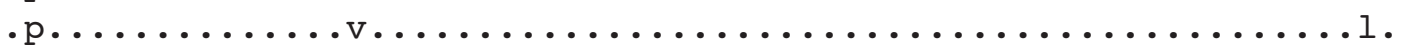

MPYGTRYPTLAFHTGGVGESDDGMPPQPFETFCYDSALLQAKIENFNIVPYTSVLPKELFGNILP

66

130

C. pneumoniae

C. muridarum

C. trachomatis L2

C. trachomatis $\mathrm{D}$

C. trachomatis B

C. trachomatis A

Ct ancestor

VDTCVKSFKHGAVLEVIMAGRGAALSDGTHAIATGIGICWGKDKNGELIGGWAAEYVEFFPTWIN

.q.t.f.........k...vae..q......................d

.q.t.f............tvt...q....v..................d

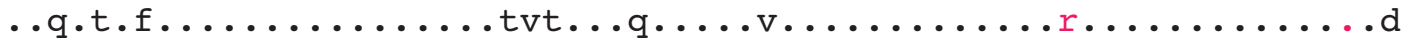

.q.t.f...........tvt...q....v..................d

.q.t.f............tvt...q......................d

VDQCTKFFKHGAVLEVIMAGRGATVTDGTQAIATGVGICWGKDKNGELIGGWAAEYVEFFPTWID

131

195

\section{C. pneumoniae \\ C. muridarum \\ C. trachomatis L2 \\ C. trachomatis D \\ C. trachomatis $\mathrm{B}$ \\ C. trachomatis A \\ Ct ancestor}

\section{Figure I}

Alignment of $C$. pneumoniae AaxB sequence with orthologs from C. muridarum Nigg, C. trachomatis L2/434, D/ UW-3, B/Jali, and A/HAR-I3. Conserved amino acid residues are indicated by dots, while differences in the chlamydial sequences are indicated by lower-case symbols. The bottom row of the alignment shows an ancestral sequence for the $C$. trachomatis aaxB genes that was predicted using the codeml program, as described in the text. The ochre ${ }^{128}$ nonsense codon in the $C$. trachomatis L2/434 sequence is indicated by an asterisk, and the column of corresponding amino acids is colored red. The column of residues corresponding to Arg and Gly ${ }^{115}$ is also colored red. Sequence accession numbers are listed in Table 5. 


\section{Results and discussion}

Expression of the aax genes in C. trachomatis L2/434

cDNAs were prepared from chlamydial cells harvested 24 $\mathrm{h}$ post-infection. PCR amplification of intergenic regions showed that the aaxA and aaxB genes were transcribed on the same mRNA, as were the $a a x B$ and $a a x C$ genes (Figure $2 \mathrm{~A}$ and $2 \mathrm{~B}$ ). No amplified product was detected for the region upstream of $a a x A$ or downstream of $a a x C$, suggesting that these three genes are coordinately transcribed in a single operon. A canonical Shine-Dalgarno sequence (ribosome binding site) preceded each putative initiator codon. The aaxABC gene cluster is conserved in all Chlamydia spp. genome sequences, and this operon is predicted to coordinately express all three genes from a polycistronic mRNA.

To determine the time course of aaxABC expression, cDNAs were prepared from RNA isolated 8,24 or $46 \mathrm{~h}$ post-infection. As a control, cDNAs also were prepared from RNA isolated from a mock infection, containing only host cells. Amplification of an intragenic region of the constitutively expressed $h s p 60$ gene confirmed the specificity and sensitivity of the analysis (Figure 2C). Amplification of intragenic regions of the $\operatorname{aax} A, \operatorname{aax} B$, or $a a x C$ cDNAs showed significant levels of expression 24 and 46 $\mathrm{h}$ post-infection, but failed to detect expression during the early stage at $8 \mathrm{~h}$ (Figure 2D). Therefore, all three genes of the AAX system are preferentially transcribed at the midor late-stages of infection, when EBs begin to form. These results are consistent with expression profiles reported from microarray studies of global gene expression $[23,25]$. Although the semi-quantitative transcript analysis shown in Figure 2D indicates that levels of aaxC expression are the same or lower than aaxA levels, we cannot rule out the possibility of multiple, unidentified promoters in this gene cluster.
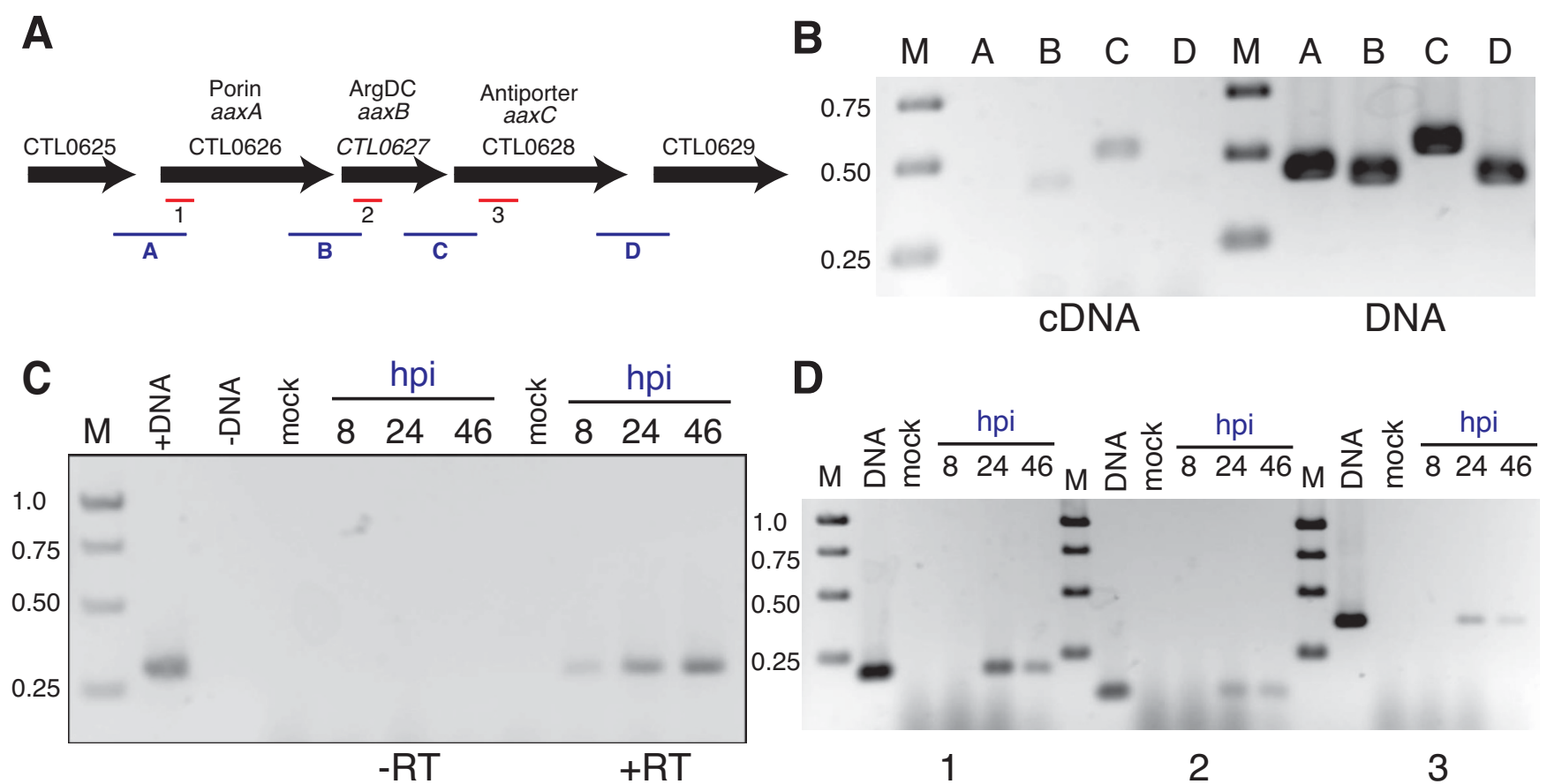

Figure 2

Analysis of aaxABC expression in C. trachomatis L2/434. Part A shows a map of the putative CTL0626-CTL0628 operon, comprising the aaxABC gene cluster. Both intragenic regions (bars I-3 shown in red) and intergenic regions (bars A-D shown in blue) were amplified by RT-PCR. Part B shows PCR amplification products for the intergenic regions identified in part A using either cDNA, prepared from $24 \mathrm{~h}$ cultures of $C$. trachomatis L2/434, or chromosomal DNA as a template. Part $C$ shows the PCR amplification products for the constitutively expressed hsp60 gene, using cDNA prepared from uninfected cells (mock) or C. trachomatis L2-infected cells harvested at the indicated hours post infection (hpi). Control reactions were performed using DNA (left lanes) or omitting reverse transcriptase (-RT) prior to PCR analysis. Part D shows gene-specific RTPCR products to semi-quantitatively assess transcript levels during the course of infection. The numbered reactions correspond to the regions shown in part A. Control DNA reactions are shown in the left-hand lanes of each section, next to mock infection controls. Marker lanes (M) shows bands corresponding to $0.25,0.50,0.75$ or $1.0 \mathrm{kbp}$ DNA standards, as indicated. All PCR products were separated on $1.5 \%$ agarose electrophoresis gels and stained using ethidium bromide. The images were cropped, inverted and adjusted for contrast and brightness using Photoshop CS3 software (Adobe). 


\section{Heterologous expression of AaxB from L2 and D strains} To test whether the L2/434 CTL0627 (aaxB) gene encodes an active, truncated AaxB protein or is a true pseudogene, the CTL0627 and CTL0628 (aaxC) genes were cloned in a multi-copy plasmid vector. An E. coli strain missing the native adiAYC arginine uptake and decarboxylase genes was used to express AaxB fused to amino-terminal T7epitope and hexahistidine tags, and untagged AaxC. Immunoblotting found no epitope-tagged protein in lysates of this strain (Figure 3), and no arginine decarboxylase activity was detected in cell-free extracts. Therefore the L2/434 aaxB homolog acts as a pseudogene in E. coli. No candidate for a suppressor tRNA was reported in the L2/434 genome sequence [10] or identified using the tRNAscan-SE program (ver. 1.23, general, cove only model) [26].

For comparison, the CT373 (aaxB) and CT374 (aaxC) genes from $C$. trachomatis D/UW-3 were expressed from

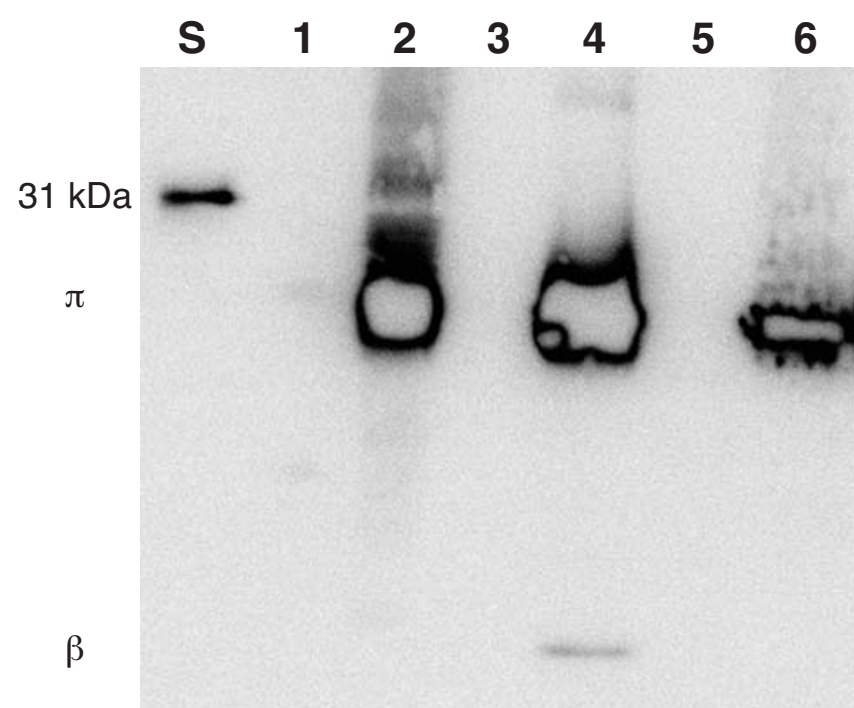

Figure 3

Full-length AaxB proteins were detected in immunoblots of $E$. coli extracts using T7-Tag monoclonal antibody. A 31-kDa T7-Tag protein standard was loaded in lane $S$ (Novagen). Lane I contained I I $2 \mu \mathrm{g}$ extract from $E$. coli DEG0I47 (pDG479), containing the wild-type L2/434 aax $B$ pseudogene fused to an amino-terminal T7-Tag. Lane 2 contained $30 \mu \mathrm{g}$ extract from $E$. coli DEG0147 (pDG543) expressing the $X^{128} \mathrm{~W}$ variant of aaxB from strain $L 2 / 434$. Lane 3 contained protein size standards (without an epitope tag). Lane 4 contained $0.7 \mu \mathrm{g}$ affinity-purified $X^{128} \mathrm{~W}$ variant of AaxB from strain L2, including a small amount of cleaved $\beta$-subunit. Lane 5 contained II $7 \mu$ g extract from $E$. coli DEG0I47 (pBAD/HisA) as a negative control. Lane 6 contained $72 \mu \mathrm{g}$ extract from $E$. coli DEG0I47 (pDG558) expressing the epitope-tagged aaxB from strain D/UW-3. The image was saturated to detect low levels of protein expression or cleavage, and it was processed as described for Figure 2. the same vector, producing T7-tagged AaxB protein in cell lysates (Figure 3). However, this pyruvoyl-dependent arginine decarboxylase must be cleaved to produce active enzyme, and no epitope-tagged cleavage product was detected by immunoblotting. Presumably due to the lack of self-cleavage, no arginine decarboxylase activity was detected in these cell-free extracts either. In contrast, the $C$. pneumoniae AaxB protein was significantly activated in E. coli [18].

\section{Restoration of AaxB activity by site-directed mutagenesis}

The C. trachomatis AaxB protein sequences share 89\% amino acid identity and $97 \%$ similarity with the active $C$. pneumoniae ortholog (Figure 1). Therefore site-directed mutagenesis was used to replace the ochre codon at position 128 of the L2/434 aaxB pseudogene with a tryptophan codon that is found in the C. pneumoniae and other C. trachomatis homologs. This $\mathrm{X}^{128} \mathrm{~W}$ variant protein was expressed at high levels in E. coli extract, and the affinity-purified protein contained epitope-tagged $\beta$-subunit (Figure 3 ). This purified protein contained a mixture of proenzyme and $41 \%$ cleaved protein forming $\alpha$ - and $\beta$ subunits (Figure 4), compared to $57 \%$ cleaved protein from C. pneumoniae. The purified $\mathrm{X}^{128} \mathrm{~W}$ variant protein catalyzed the decarboxylation of L-arginine with a $\mathrm{pH}$ optimum near 3.4, as observed for the C. pneumoniae AaxB [18]. Accounting for only the cleaved portion of protein, this $\mathrm{X}^{128} \mathrm{~W}$ variant had a $K_{\mathrm{M}}$ of $5.4 \mathrm{mM}$ and a $k_{\text {cat }}$ of $2.3 \mathrm{~s}^{-}$ 1 , compared to a $K_{\mathrm{M}}$ of $5.0 \mathrm{mM}$ and a turnover of $6.9 \mathrm{~s}^{-1}$ for C. pneumoniae AaxB.

Affinity-purified AaxB from D/UW-3 contained only proenzyme (Figure 4), yet this protein differs from the active $\mathrm{X}^{128} \mathrm{~W}$ L2/434 protein in only two amino acid positions (Figure 1). The Val155Ile substitution is conservative, and probably reflects the ancestral state. However, a Gly ${ }^{115}$ Arg substitution occurred after the divergence of the C. trachomatis L2 and A-D serovars. In the structure of the homologous arginine decarboxylase from Methanocaldococcus jannaschii [27], the corresponding Ile $\mathrm{e}^{107}$ residue is found near the N-terminal end of $\beta$-strand 6 in the $\alpha$-subunit. This strand forms the edge of one sheet in the $\alpha \beta \beta \alpha$ sandwich fold, and provides the Glu ${ }^{109}$ carboxylate group that facilitates cleavage in this protein family [28]. The Gly ${ }^{115}$ Arg replacement in C. trachomatis AaxB could alter the conformation of this $\beta$-strand, inhibiting cleavage. To test the significance of this substitution, site-directed mutagenesis was used to construct an $\mathrm{Arg}^{115} \mathrm{Gly}$ variant of the D/UW-3 protein. The affinity-purified protein was $61 \%$ cleaved, and it catalyzed L-arginine decarboxylation with a rate of $1.3 \mathrm{~s}^{-1}$ (Figure 4 ).

\section{Arginine uptake activity of AaxC transporters}

E. coli adiAYC mutants that express the C. pneumoniae aaxC gene can exchange $\mathrm{L}-\left[{ }^{3} \mathrm{H}\right]$-arginine for cytoplasmic 


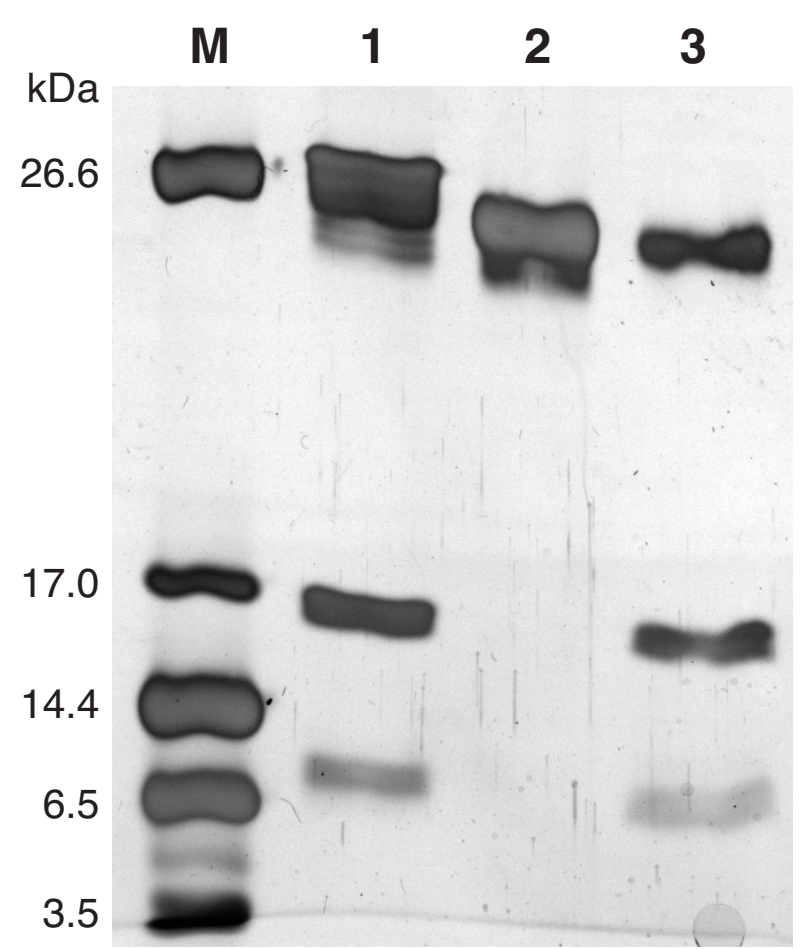

Figure 4

SDS-PAGE analysis of affinity-purified proteins shows the AaxB variant proteins self-cleaved in $E$. coli. Lane $M$ contains polypeptide markers (Bio-Rad). Lane I contains the $X^{128} \mathrm{~W}$ variant of $\mathrm{His}_{6}-\mathrm{AaxB}$ from strain $\mathrm{L} 2 / 434$, including proenzyme ( $26 \mathrm{kDa}$ expected, $26 \mathrm{kDa}$ observed), $\alpha$-subunit ( $16 \mathrm{kDa}$ expected, $16 \mathrm{kDa}$ observed) and $\beta$-subunit ( $10 \mathrm{kDa}$ expected, $8 \mathrm{kDa}$ observed). Lane 2 contains His ${ }_{10}-\mathrm{AaxB}$ from strain D/UW -3 , including only proenzyme ( $24 \mathrm{kDa}$ expected, $25 \mathrm{kDa}$ observed). Lane 3 contains the $\mathrm{R}^{115} \mathrm{G}$ variant of His ${ }_{10}$ AaxB from strain D/UW-3, including proenzyme (25 $\mathrm{kDa}$ expected, $25 \mathrm{kDa}$ observed), $\alpha$-subunit ( $16 \mathrm{kDa}$ expected, $16 \mathrm{kDa}$ observed) and $\beta$-subunit ( $9 \mathrm{kDa}$ expected, $6 \mathrm{kDa}$ observed). The gel was stained with silver, and the image was processed as described for Figure 2.

arginine [17]. To test the function of C. trachomatis AaxC proteins, arginine uptake assays were performed using $E$. coli cells expressing the aaxBC genes from L2/434 and D/ UW-3 strains (Figure 5). No significant arginine uptake was detected in cells expressing L2/434 wild-type or $\mathrm{X}^{128 \mathrm{~W}}$ aaxBC genes. However, cells expressing D/UW-3 strain $a a x B C$ genes showed significantly enhanced uptake. Although the L2/434 and D/UW-3 AaxC proteins are 99\% identical, the 7 amino acid substitutions appear to have reduced the $\mathrm{L} 2 / 434$ protein's transport activity. These substitutions are scattered across the protein sequence, and none occurs at a conserved site in an alignment of homologs.

\section{Evolution of aaxABC genes in the Chlamydiales}

Most mutations predicted to convert protein-coding genes to pseudogenes are nonsense or frameshift mutations that

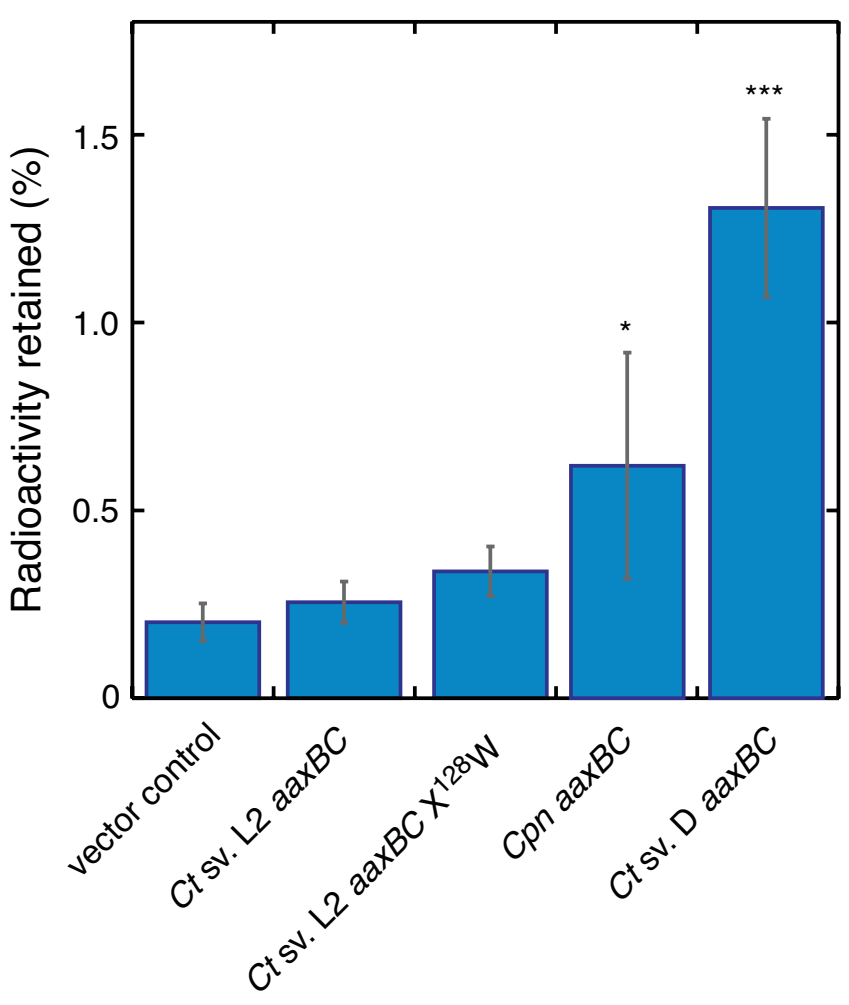

Figure 5

Arginine uptake activity in $E$. coli cells expressing chlamydial AaxB and AaxC proteins. L-[2,3,4,5$\left.{ }^{3} \mathrm{H}\right]$ Arginine was added to suspensions of $E$. coli DEG0 I47 cells during $20 \mathrm{~min}$ incubations at $37^{\circ} \mathrm{C}$. The relative radioactivity retained on filters is shown for the mean of three samples, with the corresponding standard deviations. The indicated genes were expressed from vectors $\mathrm{PBAD} / \mathrm{His} \mathrm{A}$ (negative control), pDG479 (L2/434 aaxBC), pDG543 (L2/ 434 aaxB $X^{128 W}$-aaxC), pDG379 (C. pneumoniae aaxBC), and PDG558 (D/UW-3 aaxBC). Similar levels of radioactivity were measured in samples containing $E$. coli with $\mathrm{PBAD} / \mathrm{His} A$ and control reactions with no cells. One-way ANOVA was used to identify significant differences among the samples, with Dunnett's multiple comparison post-test. A significant difference in samples expressing $C$. pneumoniae aax $B C$ (relative to $\mathrm{pBAD} / \mathrm{HisA}$ ) is indicated by $*, p \leq 0.05$; an extremely significant difference in samples expressing $C$. trachomatis $D /$ UW-3 aaxBC is indicated by ***, $p<0.001$.

prevent translation of full-length protein. However, the frequency of missense mutations may be much higher these proteins can still be expressed, and they may fold correctly, yet they can be functionally impaired [29]. Several strategies have been developed to identify detrimental missense mutations, using either protein structure models or comparative sequence analysis to predict the effects of amino acid substitutions [15]. These models show great promise in predicting the effects of nonsynonymous single nucleotide polymorphisms in well-characterized human genes [30]. When the predicted ancestral C. tracho- 


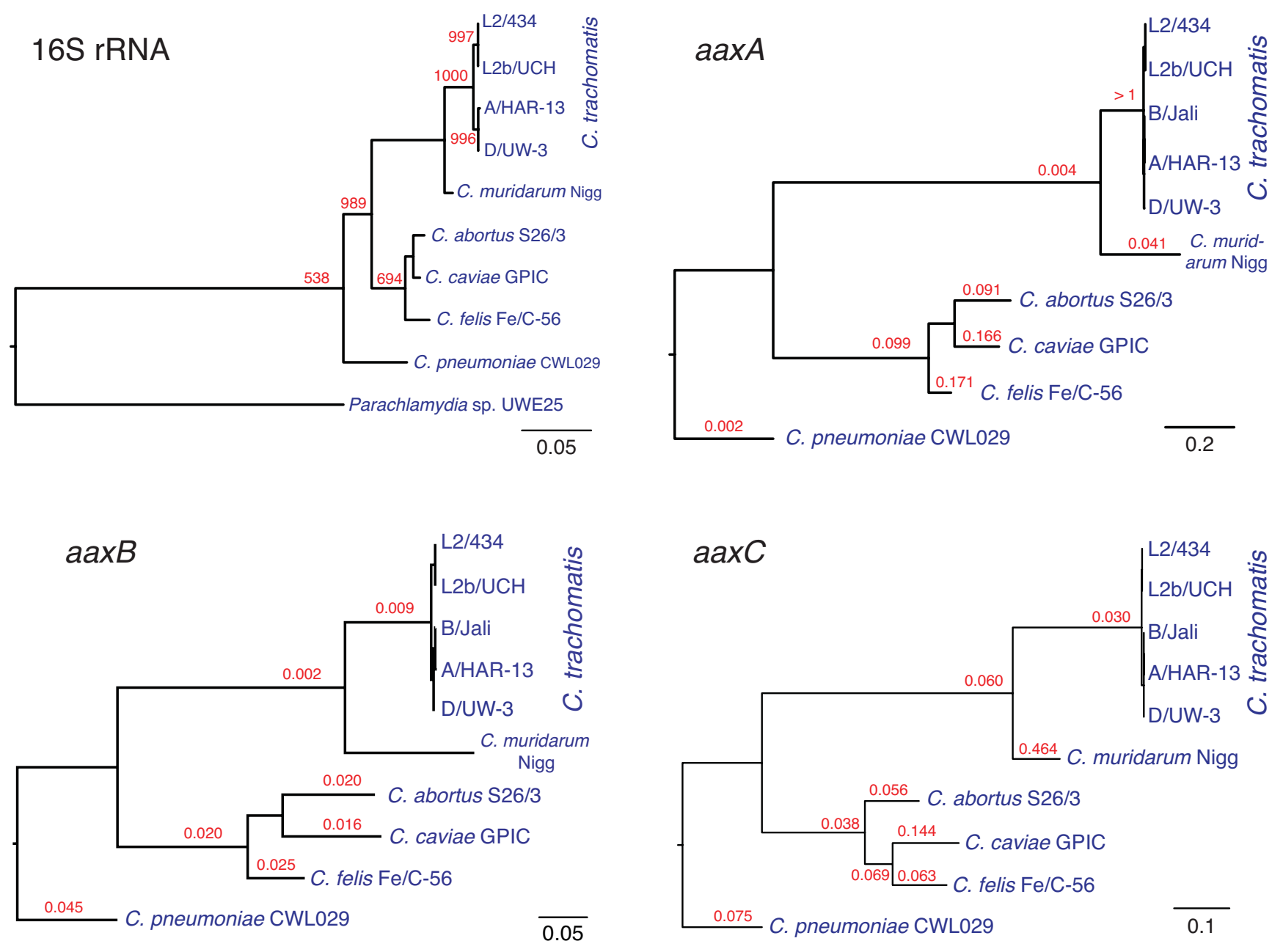

Figure 6

The chlamydial aaxABC genes have been vertically inherited and maintained under selective pressure. The phylogeny of chlamydial I6S ribosomal RNA genes (shown at the upper left) was inferred by the maximum likelihood method using the PhyML program to analyze aligned sequences from the ribosomal database project (RDP) [33,54]. Bootstrap values from 1000 replicates are shown in red for each lineage supported by a plurality of trees, and this tree was rooted using the Parachlamydia sp. UWE25 rRNA sequence. A tree calculated by the weighbor method has the same topology (phylogram from RDP not shown). The phylogenies of the aaxA, aaxB and aax $C$ genes and $d_{N} / d_{S}$ values for each lineage (shown in red) were inferred using maximum likelihood methods, as described in the text. No $d_{N} / d_{S}$ values are shown for lineages with fewer than 0.05 nucleotide substitutions per codon. For each tree, the scale bar indicates the number of nucleotide substitutions per position.

matis AaxB sequence (Figure 1) was submitted to the Sorting Intolerant From Tolerant (SIFT) web server http:// sift.jcvi.org/, the $\mathrm{G}^{115 \mathrm{R}}$ replacement was "predicted to affect protein function" [31]. However, when the C. pneumoniae AaxB sequence was submitted to the SIFT web server with a list of 22 observed replacements in the C. trachomatis sequence, all of the changes were predicted to be "tolerated." The $\mathrm{G}^{115} \mathrm{R}$ replacement alone also was predicted to be tolerated in the C. pneumoniae AaxB sequence. The PMUT server http://mmb2.pcb.ub.es:8080/PMut/ predicted 8 of the 22 replacements (including $G^{115} R$ ) to be "pathological" for the C. pneumoniae sequence [32]. Therefore these amino acid substitution prediction tools are neither sensitive nor specific enough to predict functional changes due to missense mutations in significantly diverged bacterial sequences.

Since we could not recognize specific missense mutations that impair function, we considered whether aberrant phylogenies or high rates of nonsynonymous substitution correspond to loss of function. Phylogenies of the aax $A B C$ genes have the same topologies as the $16 \mathrm{~S}$ ribosomal RNA 
Table I: List of microorganisms and plasmids

\begin{tabular}{|c|c|c|}
\hline Strain or plasmid & Description and partial genotype & Reference or source \\
\hline Chlamydia pneumoniae & Kajaani 6 & {$[52]$} \\
\hline C. trachomatis $\mathrm{L} 2 / 434$ & Lymphogranuloma venerum II serovar L2, strain 434 & H. Caldwell \\
\hline C. trachomatis D/UW-3 & Trachoma serovar D, strain UW-3/Cx & P. Wyrick \\
\hline \multicolumn{3}{|l|}{ Escherichia coli } \\
\hline BL2I(DE3) & Expression strain with T7 RNA polymerase gene & Novagen \\
\hline DEG0I47 & MGI655 $\triangle a d i A Y C:: k a n$ & {$[17]$} \\
\hline $\mathrm{DH} 5 \alpha$ & General cloning host & Invitrogen \\
\hline XLI-Blue & General cloning host & Stratagene \\
\hline \multicolumn{3}{|l|}{ Plasmids } \\
\hline pBAD/HisA & Expression vector with $\mathrm{P}_{\mathrm{BAD}}$ promoter & Invitrogen \\
\hline pDFclonel & L2/434 CTL0627-0628 in PGEM-T & This work \\
\hline pDG379 & Cpn aaxBC in pBAD/HisA & [17] \\
\hline pDG479 & L2/434 CTL0627-0628 in pBAD/HisA & This work \\
\hline PDG49I & L2/434 His ${ }_{10}-\mathrm{CTL0627}$ in pET-19b & This work \\
\hline pDG543 & pDG479 with $X 128 \mathrm{~W}$ substitution & This work \\
\hline pDG558 & $\mathrm{D} / \mathrm{WW}-3 \mathrm{His}_{6}-\mathrm{CT} 373-374$ in pBAD/HisA & This work \\
\hline PTGI7 & D/UW-3 His $10-C T 373$ in $p E T-19 b$ & This work \\
\hline PTG20 & D/UW-3 His ${ }_{10}-\mathrm{CT} 373 \mathrm{Arg}^{115} \mathrm{Gly}$ in PET-19b & This work \\
\hline
\end{tabular}

tree (Figure 6) [33]. The intact aaxABC genes from Chlamydia psittaci 6BC are highly similar to their C. abortus homologs, containing several conservative amino acid replacements (data not shown). These results are consistent with previous protein-sequence based phylogenies that indicated the three genes were acquired by the Chlamydiaceae ancestor through horizontal gene transfer after its divergence from the Parachlamydiaceae $[17,18]$. To measure the effects of purifying selection on these genes, $d_{N} / d_{S}$ values were calculated for each branch. Genes sub- ject to negative selection often have low $d_{N} / d_{S}$ values due to the costs of nonsynonymous substitutions, while genes under relaxed selection can have $d_{N} / d_{S}$ values approaching 1; genes under positive selection for diversification occasionally have $d_{N} / d_{S}$ values greater than 1 [34]. In a canonical model for gene loss and decay in intracellular bacteria, inactivating mutations that are fixed in a population give rise to pseudogenes that evolve neutrally, with a high frequency of deletions, increased $d_{N} / d_{S}$ values and biased GC to AT mutations [35,36].

Table 2: Primers used for cloning and sequencing

\begin{tabular}{|c|c|}
\hline Primer name & Sequencel \\
\hline CTL06263'F & GCTCCAGACTTCCAACTC \\
\hline CTL06295'R & TGTAAAGCCATGAAGAAGG \\
\hline 5 СТ $373 \mathrm{X}$ & CGGCTCGAGATGCCTTACGGAACTCG \\
\hline $3 \mathrm{CT} 374 \mathrm{H}$ & GCAAGCTTACAAATGGATTTTATTAGC \\
\hline $5 \mathrm{CT} 373 \mathrm{~N}$ & GGTCATATGCCTTACGGAACTCG \\
\hline 3СТ373B & GCTGGATCCTTATTGGATAACAGCAGGC \\
\hline $5 \mathrm{CT} 373 \times 128 \mathrm{~W}$ & CAGAATACGTAGAGTTTTTCCCAACTTGGATCGATGATGAAATCGCAGAAT \\
\hline $3 \mathrm{CT} 373 \times 128 \mathrm{~W}$ & ATTCTGCGATTTCATCATCGATCCAAGTTGGGAAAAACTCTACGTATTCTG \\
\hline 5 СТ $372 X$ & GGGCTCGAGATGTCCTTCCGTTCGGTTTTAC \\
\hline 3CT374R & CGCGAATTCTTACAAATGGATTTTATTAGC \\
\hline 5CT373RII5G & GGAGAGCTCATCGGGGGCTGGGCAG \\
\hline $3 C T 373 R I I 5 G$ & CTGCCCAGCCCCCGATGAGCTCTCC \\
\hline pBAD-Fwd2 & CGTCACACTTTGCTATGC \\
\hline pBAD-Rev & GATTTAATCTGTATCAGGCTG \\
\hline CTseql & GATCAGCTACATGATCGGAG \\
\hline CTseq2 & TCAGTACTCACTCTATGCAATAG \\
\hline CTseq3 & CCGTGTTTATAGCGTGCGAGC \\
\hline CTseq4 & GTGATCAGCTCCATGATCG \\
\hline T7-Promoter & GTAATACGACTCACTATAGGG \\
\hline T7-Term & GCTAGTTATTGCTCAGCGG \\
\hline
\end{tabular}

I Restriction sites are underlined and the initiator codon is shown in italics. 
Table 3: Primers used for operon RT-PCR

\begin{tabular}{clllll}
\hline Reaction & Genes & Primer names & Forward primer sequence & Reverse primer sequence \\
\hline A & CTL0625 to 626 & $\begin{array}{l}\text { CTL06253'F/ } \\
\text { CTL06265'R }\end{array}$ & GCTCATTAGCAACGAAGCC & GCGCTTGCTTGAGATTTC \\
B & CTL0626 to 627 & $\begin{array}{l}\text { CTL06263'F/ } \\
\text { CTL06275'R }\end{array}$ & GCTCCAGACTTCCAACTC & GACTTCTAATACAGCACCATGTTTG \\
C & CTL0627 to 628 & $\begin{array}{l}\text { CTL06273'F/ } \\
\text { CTL06285'R }\end{array}$ & GCATAGTGAGTTCCAATATTTC & GGTGGGAAGAAATAGTTAAGG \\
D & CTL0628 to 629 & CTL06283'F/ & CGATCATGGCTCTTG & TGTAAAGCCATGAAGAAGG & 50I \\
\end{tabular}

For branches in the aaxA gene tree, $d_{S}$ values ranged from $<0.005$ (among the C. trachomatis strains) to 66 (saturation, separating the Chlamydophila and Chlamydia lineages). $d_{N} / d_{S}$ values range from 0.002 to more than 1 , with the majority of lineages showing purifying selection (Figure 6). The highly diverged amino-terminal secretory signal sequence in C. trachomatis homologs accounted for most of the nonsynonymous substitutions. Otherwise, the $d_{N} / d_{S}$ values for aaxA homologs are consistent with those of the major outer membrane protein (MOMP) porin. The $d_{N} / d_{S}$ value was 0.114 for the C. trachomatis $\mathrm{D} /$ UW-3 and C. pneumoniae MOMP pair, and 0.144 for the C. trachomatis D/UW-3 and L2/434 MOMP sequences. From these data we infer that aaxA orthologs have been subjected to moderate purifying selection, punctuated by a dramatic change in the secretory signal region of the ancestral C. trachomatis and C. muridarum gene. Signal sequences can vary significantly among homologous proteins [37], so further experiments will be required to test whether these changes in the signal sequence alter protein localization or expression levels. A future site-based comparison of codon substitution rates could identify specific positions subject to relaxed selection, but will require many more aaxA sequences.

Despite the inactivating nonsense and missense mutations in C. trachomatis aaxB genes, the $d_{S}$ values for aaxB genes ranged from $<0.00005$ in the $C$. trachomatis lineage to 14 separating the Chlamydia and Chlamydophila strains. There are correspondingly few nonsynonymous substitu- tions, so $d_{N} / d_{S}$ values are uniformly low (Figure 6). The frequency of GC versus AT nucleotides was not substantially different at any codon position in the inactivated genes. As observed for several Rickettsial pseudogenes, gene inactivation does not always correspond to higher $d_{N} / d_{S}$ values [38]. The aaxC gene also shows no sign of relaxed selection, even in the $C$. trachomatis lineages with saturating synonymous substitution rates. Although homologs in C. trachomatis B/Jali and A/HAR-13 strains have 2 or 3 deletions, respectively, there are no other nucleotide substitutions compared to the $\mathrm{D} / \mathrm{UW}-3$ strain. Neutral evolution may be difficult to detect following such recent gene inactivation.

\section{Parallel loss of AAX activity in C. trachomatis strains correlates with modes of infection}

While the AAX system from C. pneumoniae functions in $E$. coli, we have demonstrated that several homologous $C$. trachomatis genes have experienced inactivating mutations. The pathogenic Chlamydiales form two distinct phylogenetic groups: the Chlamydophila and Chlamydia genera [39]. The latter includes C. trachomatis and Chlamydia muridarum, a strain that causes mouse pneumonitis. An alignment of AaxB sequences shows that the C. muridarum homolog contains none of the deleterious mutations found in C. trachomatis genes, so it should form an active arginine decarboxylase (Figure 1). Furthermore, a peptide from the AaxC transporter of this strain was identified bound to MHC class I molecules from infected murine dendritic cells [40]. These data indicate the chlamydial

Table 4: Primers used for single gene RT-PCR

\begin{tabular}{|c|c|c|c|c|c|}
\hline Reaction & Genes & Primer names & Forward primer sequence & Reverse primer sequence & Size (bp) \\
\hline & hsp60 (groEL_l) & hsp3/hsp4 & GACCGCCAGTTAAGATAGCG & TCTCTAGCTACTTCGCAACAAATCC & 297 \\
\hline I & CTL0626 & $\begin{array}{l}\text { CTL06265'F/ } \\
\text { CTL06265'R }\end{array}$ & GCACACCATCACTATCAC & GCGCTTGCTTGAGATTTC & 226 \\
\hline 2 & CTL0627 & $\begin{array}{l}\text { CTL06275'F/ } \\
\text { CTL06275'R }\end{array}$ & GTTGGCGAGTCCGATGATG & GACTTCTAATACAGCACCATGTTTG & 195 \\
\hline 3 & CTL0628 & $\begin{array}{l}\text { CTL06285'F/ } \\
\text { CTL06285'R }\end{array}$ & GAAACGGTCTCCTACTAGC & GGTGGGAAGAAATAGTTAAGG & 357 \\
\hline
\end{tabular}


Table 5: Sequences used for phylogenetic analysis and substitution rate calculations

\begin{tabular}{|c|c|c|c|}
\hline \multirow[t]{2}{*}{ Strain } & \multicolumn{3}{|c|}{ Chromosomal locus and GenBank RefSeq accession number } \\
\hline & $\operatorname{aax} A$ & $a a x B$ & $\operatorname{aaxC}$ \\
\hline Chlamydia abortus S26/3I & $\begin{array}{c}\text { CAB696 } \\
\text { [YP 220094.I] }\end{array}$ & $\begin{array}{c}\text { CAB697 } \\
\text { [YP 220095.1] }\end{array}$ & $\begin{array}{c}\text { CAB698 } \\
{[\text { [YP 220096.1] }}\end{array}$ \\
\hline Chlamydia caviae GPICI & $\begin{array}{c}\text { CCA00729 } \\
{[N P \text { 829592.1] }}\end{array}$ & $\begin{array}{c}\text { CCA00730 } \\
{[N P \text { 829593.1] }}\end{array}$ & $\begin{array}{l}\text { CCA0073I } \\
{[N P \text { 829594.1] }}\end{array}$ \\
\hline $\begin{array}{l}\text { Chlamydia felis } \\
\text { Fe/C-56 }\end{array}$ & $\begin{array}{c}\text { CF0287 } \\
\text { [YP 515204.I] }\end{array}$ & $\begin{array}{c}\text { CF0286 } \\
\text { [YP 5I5203.1] }\end{array}$ & $\begin{array}{c}\text { CF0285 } \\
\text { [YP 515202.1] }\end{array}$ \\
\hline Chlamydia muridarum Nigg & $\begin{array}{c}\text { TC065I } \\
\text { [NP 297025.1] }\end{array}$ & $\begin{array}{c}\text { TC0652 } \\
{[\mathrm{NP} 297026.1]}\end{array}$ & $\begin{array}{c}\text { TC0653 } \\
{[\text { NP 297027.I] }}\end{array}$ \\
\hline Chlamydia pneumoniae CWL029I & $\begin{array}{c}\text { CPn I033 } \\
{[N P \text { 225227.I] }}\end{array}$ & $\begin{array}{c}\text { CPn } 032 \\
{[N P \text { 225226.I] }}\end{array}$ & $\begin{array}{c}\text { CPn I031 } \\
{[N P \text { 225225.1] }}\end{array}$ \\
\hline Chlamydia trachomatis A/HAR-13 & $\begin{array}{l}\text { CTA_0404 } \\
\text { [YP 328186.1] }\end{array}$ & $\begin{array}{l}\text { CTA_0405 } \\
\text { [YP 328187.1] }\end{array}$ & $(\text { CTA_0406) })^{3}$ \\
\hline Chlamydia trachomatis B/Jali & $\mathrm{NA}^{2}$ & $\mathrm{NA}^{2}$ & $\mathrm{NA}^{2,3}$ \\
\hline Chlamydia trachomatis D/UW-3 & $\begin{array}{c}\text { CT372 } \\
\text { [NP 21988I.1] }\end{array}$ & $\begin{array}{c}\text { CT373 } \\
\text { [NP 219882.1] }\end{array}$ & 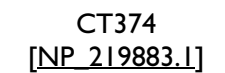 \\
\hline Chlamydia trachomatis L2/434 & $\begin{array}{l}\text { CTL0626 } \\
\text { [YP } 001654701.1]\end{array}$ & $\left(\mathrm{CTL0627)^{3 }}\right.$ & $\begin{array}{c}\text { CTL0628 } \\
\text { [YP } 001654702.1]\end{array}$ \\
\hline Chlamydia trachomatis $\mathrm{L} 2 \mathrm{~b} / \mathrm{UCH}$ & $\begin{array}{l}\text { CTLon_0624 } \\
{[\text { YP } 0016537 \mid 3.1 \text { ] }}\end{array}$ & $\left(\right.$ CTLon_0625) ${ }^{3}$ & $\begin{array}{l}\text { CTLon_0626 } \\
\text { [YP 0016537|4.1] }\end{array}$ \\
\hline
\end{tabular}

\footnotetext{
I These species are sometimes considered part of the Chlamydophila genus.

${ }^{2}$ Not available. The unannotated C. trachomatis B/Jali genome sequence was retrieved from the Sanger Institute website http://www.sanger.ac.uk/ Projects/C trachomatis/.

${ }^{3}$ The aaxB pseudogenes in LGV strains and the aaxC pseudogenes in C. trachomatis HAR-I3 and Jali strains were not assigned GenBank accession numbers.
}

ancestor had a functional AAX system, but independent mutations in the C. trachomatis homologs are progressively inactivating these genes. Recent demonstrations of gene transfer and recombination among chlamydiae temper the correlation between serotype and AAX functionality [13]. Future sequences from clinical isolates and additional chlamydial species will help define the distribution and evolution of the AAX system.

In early stage acute respiratory infections, C. pneumoniae EBs infect granulocytes and alveolar macrophages, which both use arginine to produce nitric oxide [41-43]. Therefore the AAX system may be selected for its ability to reduce $\mathrm{L}$-arginine levels and nitric oxide synthase activity during infection. C. pneumoniae, unlike C. trachomatis, can infect and replicate in neutrophil granulocytes [44]. C. trachomatis strains rarely cause pneumonia, except in infants, who have immature alveolar macrophages [45]. Instead, C. trachomatis strains primarily infect mucosal epithelial cells, which do not express the inducible nitric oxide synthase; however, disseminating C. trachomatis L2 cells can persist in unactivated macrophages [46]. Consistent with this model, mice deficient in inducible nitric oxide synthase resolved genital C. trachomatis infections as well as normal mice [47].

A similar relationship between chlamydial strain-specific metabolism and tissue tropism has been described for tryptophan biosynthesis. When IFN- $\gamma$ is produced by the host during infection, it causes the expression of indoleamine 2,3-dioxygenase (IDO), which degrades Ltryptophan. Genital tract isolates of $C$. trachomatis serovars $\mathrm{B}, \mathrm{D}-\mathrm{K}$ and $\mathrm{L} 2$ produce tryptophan synthase to make tryptophan from exogenous indole. In contrast, ocular C. trachomatis serovars $\mathrm{A}, \mathrm{Ba}$ and $\mathrm{C}$ contain a deletion mutation in the $\operatorname{trp} A$ gene $[48,49]$. Despite the inactivating deletion in $\operatorname{trp} A$, both the $\operatorname{trp} A B$ genes are transcribed and translated in a serovar A strain [48]. It has been proposed that ocular C. trachomatis strains do not encounter indole or IFN- $\gamma$ induced IDO during infection [50].

\section{Conclusion}

The loss of arginine decarboxylase activity in the AaxB protein from L2/434 was predicted due to a nonsense mutation, but the inactivation of D/UW-3 AaxB was not obvious from the protein sequence. Nor could we predict that the $\mathrm{L} 2 / 434$ AaxC would be inactive, while the $\mathrm{D} / \mathrm{UW}$ 3 AaxC would be active (the two protein sequences are $99 \%$ identical). Both aaxBC orthologs are transcribed. Therefore the AAX system has been inactivated via independent mechanisms in at least two lineages of $C$. trachomatis. Proteomic evidence suggests that the AaxA outer membrane protein is produced by L2/434 cells during infection, but this porin could have additional functions that are independent of AAX system. These results suggest a cautious interpretation of gene expression data for species undergoing reductive evolution. Neither sequence comparison nor transcriptional analysis is sufficient to 
detect all pseudogenes in these bacteria. Furthermore, recently inactivated genes may not show the hallmarks of relaxed selection, leading to over prediction of bacterial metabolic capabilities. Folded into the protein sequence databases, these inactive sequences may corrupt future genome annotations and protein-structure function analyses that rely on comparative sequence analysis.

\section{Methods \\ Strains and DNA}

L2 mouse fibroblast cells were grown to confluency in Dulbecco's modified Eagle medium (DMEM) supplemented with $10 \%$ FBS (complete DMEM) at $37^{\circ} \mathrm{C}$ in $5 \%$ $\mathrm{CO}_{2}$. These cells were infected at a multiplicity of infection (MOI) of 1 with EBs from C. trachomatis D/UW-3 or L2/434 (Table 1) [51]. After $46 \mathrm{~h}$ incubation, infected cells were pooled and sonicated to isolate EBs, and chromosomal DNA was extracted using the DNeasy Tissue Kit (Qiagen, Valencia, CA). Chlamydia pneumoniae genes were previously cloned from strain Kajaani 6 [52]. Escherichia coli DH5a (Invitrogen, Carlsbad, CA) or E. coli XL1-Blue (Stratagene, La Jolla, CA) strains were used as general cloning hosts. E. coli BL21(DE3) was used to express genes from T7 promoters. E. coli DEG0147 was used to express genes from $\mathrm{P}_{\mathrm{BAD}}$ promoters.

\section{Cloning}

C. trachomatis L2/434 genomic DNA and primers CTL06263'F and CTL06295'R (Table 2) were used to amplify a $2.5 \mathrm{kbp}$ DNA fragment containing the CTL0627 $(a a x B)$ and CTL0628 (aaxC) loci plus minimal 5' and 3' flanking sequences. The purified PCR product was ligated into plasmid pGEM-T (Promega) to produce vector pDFclone1. DNA sequencing performed at the Uniformed Services University Biomedical Instrumentation Center confirmed that the cloned DNA sequence was identical to the published sequence (GenBank accession $\underline{\mathrm{NC}}$ 010287), except for a silent $\mathrm{T}^{390} \mathrm{C}$ mutation in the CTL0627 locus.

The CTL0627 and CTL0628 genes were amplified from pDFclone1 by PCR using primers 5CT373X and 3CT374H. The purified product was digested and ligated into the XbaI and HindIII restriction sites of vector pBAD/ HisA to produce vector pDG479. Sequencing reactions using the primers pBAD-Fwd2, CTseq1 and pBAD-Rev confirmed that the cloned sequence was identical to that found in pDFclone1. The CTL0627 gene was amplified from pDFclone1 by PCR using primers 5CT373N and 3CT373B. The product was ligated into the NdeI and BamHI sites of vector pET-19b to produce vector pDG491. A QuikChange site-directed mutagenesis kit (Stratagene) was used with primers 5CT373X128W and 3CT373X128W to replace the ochre codon 128 of CTL0627 in pDG479 with a tryptophan codon, resulting in vector $\mathrm{pDG} 543$.
The CT373 (aaxB) gene from C. trachomatis D/UW-3 was amplified from genomic DNA using the 5CT373N and 3CT373B primers. The resulting product was cloned into pET-19b to produce vector pTG17, as described for CTL0627. The CT373 and CT374 (aaxC) genes were amplified using primers 5CT373X and 3CT374H and ligated into $\mathrm{pBAD} / \mathrm{HisA}$, as described above, to produce vector pDG558. DNA sequencing at the Institute for Cellular and Molecular Biology DNA Core Facility showed that the DNA cloned in these vectors was identical to the published sequence (GenBank accession NC 000117). Site directed mutagenesis was used with primers 5CT373R115G and 3CT373R115G and vector pTG17 to construct an $\operatorname{Arg}^{115}$ Gly substitution in CT373, resulting in vector pTG20.

\section{Analysis of gene expression}

C. trachomatis L2/434 EBs diluted in DMEM were used to infect confluent L2 mouse fibroblast cells at an MOI of 5 (for $8 \mathrm{~h}$ samples) or an MOI of 1 (for 24 and $46 \mathrm{~h}$ samples) for $2 \mathrm{~h}$ with rocking at $37^{\circ} \mathrm{C}$ in $5 \% \mathrm{CO}_{2}$. Mock infections were performed with DMEM. Following infection, cells were incubated with complete DMEM supplemented with $20 \mu \mathrm{g} / \mathrm{ml}$ gentamicin sulfate and $1 \mu \mathrm{g} / \mathrm{ml}$ cycloheximide. Total RNA was harvested at 8, 24, and 46 h using TRIzol (Invitrogen) as directed by the manufacturer. RNA harvests were repeated in triplicate for each time period starting with independent infections. RNA was treated with amplification grade DNase I (Invitrogen) to remove contaminating DNA prior to cDNA synthesis. cDNA was synthesized from the DNase-treated RNA using the ThermoScript RT-PCR System for First-Strand cDNA synthesis kit from Invitrogen using the random primer protocol. PCR was performed using PCR MASTER MIX $(2 \times)$ (Fermentas, Glen Burnie, MD), $1 \mu$ l of cDNA or RNA or 50 ng of control genomic DNA as template, and $0.5 \mu \mathrm{M}$ each of forward and reverse primers (Tables 3 and 4 ). Thermocycler conditions were $94^{\circ} \mathrm{C}$ for $2 \mathrm{~min}, 25$ cycles of $94^{\circ} \mathrm{C}$ for $45 \mathrm{~s}, 53^{\circ} \mathrm{C}$ for $45 \mathrm{~s}$, and $72^{\circ} \mathrm{C}$ for $50 \mathrm{~s}$, and a final extension of $5 \mathrm{~min}$ at $72^{\circ} \mathrm{C}$. PCR products were analyzed on $1.5 \%$ agarose gels and visualized using ethidium bromide stain.

\section{Heterologous expression and protein purification}

E. coli BL21(DE3) cells containing the indicated plasmids were grown in LB medium supplemented with $100 \mu \mathrm{g} / \mathrm{ml}$ ampicillin and induced with $1 \% \alpha$-D-lactose to express the following decahistidine-tagged proteins: His ${ }_{10^{-}}$ CTL0627 (pDG491), His ${ }_{10^{-}}$CT373 (pTG17), and His ${ }_{10^{-}}$ CT373-R ${ }^{115}$ G (pTG20). E. coli DEG0147 cells containing plasmids derived from pBAD/HisA and induced with $0.2 \%$ L-arabinose were used to express the following hexahistidine and T7 epitope-tagged proteins: $\mathrm{His}_{6}$ CTL0267-0268 (pDG479), His $_{6}-$ CTL0627-X ${ }^{128} \mathrm{~W}$ (pDG543), and $\mathrm{His}_{6}$-CT373-374 (pDG558). The polyhistidine-tagged proteins were purified using $\mathrm{Ni}^{2+}$-affinity 
chromatography and analyzed by sodium dodecylsulfatepolyacrylamide gel electrophoresis (SDS-PAGE) as described previously [18].

\section{Arginine uptake and decarboxylation assays}

The transport of radiolabeled arginine was measured in whole cells collected by filtration, using a method that we reported previously [17]. These assays contained $1 \times 10^{9}$ E. coli cells washed and suspended in E medium ( $\mathrm{pH} 5$ ) at $37^{\circ} \mathrm{C}$ for $20 \mathrm{~min}$ with $1 \mathrm{mM} \mathrm{L}$-arginine and $2 \mu \mathrm{Ci} \mathrm{L}$ $\left[2,3,4,5-{ }^{3} \mathrm{H}\right]$ arginine. Arginine decarboxylase activity measurements using cell-free extracts or purified proteins were performed as described previously using 40 to 80 nCi L-[1-14 C]arginine [18]. ${ }^{14} \mathrm{CO}_{2}$ was trapped and then measured by liquid scintillation counting.

\section{Immunoblotting}

Proteins were separated on a SDS-PAGE Tris-glycine gel, followed by electrotransfer to a PVDF membrane (Pall, Ann Arbor, MI). These blots were blocked with bovine serum albumin and then incubated for $1 \mathrm{~h}$ with a 1:5000 dilution of T7-Tag monoclonal antibody conjugated to horseradish peroxidase (Novagen, Madison, WI). An Image Station 4000 instrument (Carestream Health, New Haven, CT) was used to detect chemiluminescence produced during incubation with SuperSignal West Pico Substrate (Thermo Pierce, Rockford, IL).

\section{Phylogenetic analysis and estimation of nucleotide substitution rates}

Orthologous nucleotide sequences for the aax $A, \operatorname{aax} B$ and aaxC genes were retrieved from the GenBank database (Table 5) and aligned using the ClustalW2 program (ver. 2.0.10) [53]. The phylogeny of the aaxA, aaxB and aaxC genes was inferred using the PhyML program (ver. 3.0.1) [54], with the HKY85 nucleotide substitution model, a discrete gamma model with 4 categories of sites and estimated transition/transversion ratios of 3.9 (aaxA), 4.8 $($ aax $C)$ and $6.1(a a x B)$. Trees were viewed and edited using the FigTree program (ver. 1.2.2, A. Rambaut, University of Edinburgh) and Illustrator CS3 (Adobe). The numbers of synonymous substitutions per synonymous site $\left(d_{S}\right)$ and nonsynonymous substitutions per nonsynonymous site $\left(d_{N}\right)$ were estimated using the codeml program from the PAML software suite (ver. 4.2) [55], based on the ClustalW2 alignment and PhyML phylogeny with a free ratio branch model ( $\omega=d_{N} / d_{S}$ varies for each branch). A user tree was supplied to the codeml program, with codon frequencies calculated from the average nucleotide frequencies at the three codon positions, and with one category in the $\omega$ distribution. Both $\omega$ and $\kappa$ parameters were estimated from the data. The codonml module was also used with the same parameters to infer the ancestral C. trachomatis AaxB sequence shown in Figure 1[55]. This ancestral sequence was consistent with a sequence inferred using the Dnapars program from the Phylip package (ver. 3.66; J. Felsenstein, U. Washington). However, the Dnapars program reported more ambiguous codons than the codeonml program. For the analysis of aaxA genes, translated amino acid sequences were aligned using ClustalW2, and then a nucleotide sequence alignment was constructed using the PAL2NAL program (ver. 12) [56]. Pairwise sequence $d_{N} / d_{S}$ ratios were calculated using the KaKs_Calculator program (ver. 1.2) [57].

\section{Authors' contributions}

TNG carried out the protein expression, purification and immunoblotting studies, performed some cloning and mutagenesis experiments, and performed arginine uptake and decarboxylation assays. DJF cultured Chlamydia, carried out gene expression experiments and initial gene cloning, and helped to draft the manuscript. DEG conceived of and coordinated the study, performed some cloning and mutagenesis experiments, phylogenetic and statistical analysis, and drafted the manuscript. All authors read and approved the final manuscript.

\section{Acknowledgements}

This work was supported in part by Public Health Service grants 5R2 IAI064444 (to DEG), 5R0IAI044033 (to Anthony T. Maurelli) and IF32AI078655-0I (to DJF). We thank Garry Myers (University of Maryland School of Medicine) for providing access to the $C$. psittaci 6BC genome sequence prior to publication.

\section{References}

I. Cook JA: Eliminating blinding trachoma. N Engl J Med 2008, 358: 1777-I779.

2. McNabb SJN, Jajosky RA, Hall-Baker PA, Adams DA, Sharp P, Worsham C, Anderson WJ, Aponte JJ, Jones GF, Nitschke DA, et al.: Summary of notifiable diseases - United States - 2006. MMWR Morb Mortal Wkly Rep 2008, 55: I-94.

3. Kuo C-C, Jackson LA, Campbell LA, Grayston JT: Chlamydia pneumoniae (TWAR). Clin Microbiol Rev 1995, 8:45I-46I.

4. Kalman S, Mitchell W, Marathe R, Lammel C, Fan J, Hyman RW, Olinger L, Grimwood J, Davis RW, Stephens RS: Comparative genomes of Chlamydia pneumoniae and C. trachomatis. Nat Genet 1999, 21:385-389.

5. Horn M, Collingro A, Schmitz-Esser S, Beier CL, Purkhold U, Fartmann B, Brandt P, Nyakatura G], Droege M, Frishman D, et al.: Illuminating the evolutionary history of chlamydiae. Science 2004 , 304:728-730.

6. Andersson SGE, Kurland CG: Reductive evolution of resident genomes. Trends Microbiol 1998, 6:263-268.

7. Ogata $H$, Audic $S$, Renesto-Audiffren P, Fournier P-E, Barbe V, Samson D, Roux V, Cossart P, Weissenbach J, Claverie J-M, Raoult D: Mechanisms of evolution in Rickettsia conorii and R. prowazekii. Science 200I, 293:2093-2098.

8. Dean D, Meyers GS, Read TD: Lessons and challenges arising from the "first wave" of Chlamydia genome sequencing. In Chlamydia: Genomics and Pathogenesis Edited by: Bavoil PM, Wyrick PB. Norfolk, UK: Horizon Bioscience; 2006: I-24.

9. Carlson JH, Porcella SF, McClarty G, Caldwell HD: Comparative genomic analysis of Chlamydia trachomatis oculotropic and genitotropic strains. Infect Immun 2005, 73:6407-64I8.

10. Thomson NR, Holden MTG, Carder C, Lennard N, Lockey SJ, Marsh P, Skipp P, O'Connor CD, Goodhead I, Norbertzcak H, et al: Chlamydia trachomatis: Genome sequence analysis of lymphogranuloma venereum isolates. Genome Res 2008, |8:|6|-|7|. 
II. Wernegreen J]: For better or worse: genomic consequences of intracellular mutualism and parasitism. Curr Opin Genet Dev 2005, I 5:572-583.

I2. Nunes A, Nogueira PJ, Borrego MJ, Gomes JP: Chlamydia trachomatis diversity viewed as a tissue-specific coevolutionary arms race. Genome Biol 2008, 9:RI53.

13. Gomes JP, Bruno WJ, Nunes A, Santos N, Florindo C, Borrego MJ, Dean D: Evolution of Chlamydia trachomatis diversity occurs by widespread interstrain recombination involving hotspots. Genome Res 2007, I 7:50-60.

14. Taverna DM, Goldstein RA: Why are proteins so robust to site mutations? I Mol Biol 2002, 3 I 5:479-484

15. $\mathrm{Ng}$ PC, Henikoff S: Predicting the effects of amino acid substitutions on protein function. Annu Rev Genomics Hum Genet 2006 , 7:61-80.

16. Zheng $D$, Gerstein MB: The ambiguous boundary between genes and pseudogenes: the dead rise up, or do they? Trends Genet 2007, 23:219-224.

17. Smith $C B$, Graham DE: Outer and inner membrane proteins compose an arginine-agmatine exchange system in Chlamydophila pneumoniae. J Bacteriol 2008, I 90:743 I-7440.

18. Giles TN, Graham DE: Characterization of an acid-dependent arginine decarboxylase enzyme from Chlamydophila pneumoniae. J Bacteriol 2007, I 89:7376-7383.

19. Kuo C-C, Grayston JT: Amino acid requirements for growth of Chlamydia pneumoniae in cell cultures: growth enhancement by lysine or methionine depletion. J Clin Microbiol 1990, 28: $1098-1100$

20. Treuhaft MW, Moulder JW: Biosynthesis of arginine in $\mathbf{L}$ cells infected with chlamydiae. J Bacteriol 1968, 96:2004-20 I I.

21. Schaumburg CS, Tan M: Arginine-dependent gene regulation via the ArgR repressor is species specific in Chlamydia. J Bac teriol 2006, I 88:919-927.

22. Mäurer AP, Mehlitz A, Mollenkopf HJ, Meyer TF: Gene expression profiles of Chlamydophila pneumoniae during the developmental cycle and iron depletion-mediated persistence. PLOS Pathog 2007, 3(6):e83.

23. Nicholson TL, Olinger L, Chong K, Schoolnik G, Stephens RS: Global stage-specific gene regulation during the developmental cycle of Chlamydia trachomatis. J Bacteriol 2003, I 85:3 I79-3 I89.

24. Birkelund S, Marie Morgan-Fisher ET, Kris Gevaert, Shaw Allan C, Christiansen Gunna: Analysis of proteins in Chlamydia trachomatis L2 outer membrane complex, COMC. FEMS Immunol Med Microbiol 2009, 55:187-195.

25. Belland RJ, Zhong G, Crane DD, Hogan D, Sturdevant D, Sharma Beatty WL, Caldwell HD: Genomic transcriptional profiling of the developmental cycle of Chlamydia trachomatis. Proc Nat Acad Sci USA 2003, 100:8478-8483.

26. Lowe TM, Eddy SR: tRNAscan-SE: a program for improved detection of transfer RNA genes in genomic sequence. Nucleic Acids Res 1997, 25:955-964.

27. Tolbert WD, Graham DE, White RH, Ealick SE: Pyruvoyl-dependent arginine decarboxylase from Methanococcus jannaschii. Crystal structures of the self-cleaved and S53A proenzyme forms. Structure 2003, I I (3):285-294

28. McElroy HE, Robertus JD: Site-directed alteration of Glu 197 and Glu66 in a pyruvoyl-dependent histidine decarboxylase. Protein Eng 1989, 3:43-48.

29. Bailey J, Manoil C: Missense mutations that inactivate Escherichia coli lac permease. J Mol Biol 1998, 277:199-2I3.

30. Chasman D, Adams RM: Predicting the functional consequences of non-synonymous single nucleotide polymor phisms: structure-based assessment of amino acid variation. J Mol Biol 200I, 307:683-706.

31. Ng PC, Henikoff S: Predicting deleterious amino acid substitutions. Genome Res 200I, I I:863-874.

32. Ferrer-Costa C, Gelpi IL, Zamakola L, Parraga I, de la Cruz X, Orozco M: PMUT: a web-based tool for the annotation of pathological mutations on proteins. Bioinformatics 2005, 21 :3 I 76-3178.

33. Cole JR, Wang Q, Cardenas E, Fish J, Chai B, Farris RJ, Kulam-Syed Mohideen AS, McGarrell DM, Marsh T, Garrity GM, Tiedje JM: The Ribosomal Database Project: improved alignments and new tools for rRNA analysis. Nucleic Acids Res 2009, 37:D|4|-|45.

34. Nielsen R: Molecular signatures of natural selection. Annu Rev Genet 2005, 39:197-218.
35. Andersson JO, Andersson SG: Genome degradation is an ongoing process in Rickettsia. Mol Biol Evol 1999, 16:1 I78-II91.

36. Darby AC, Cho N-H, Fuxelius H-H, Westberg J, Andersson SGE: Intracellular pathogens go extreme: genome evolution in the Rickettsiales. Trends Genet 2007, 23:5 I I-520.

37. von Heijne G, Abrahmsen L: Species-specific variation in signal peptide design. Implications for protein secretion in foreign hosts. FEBS Lett 1989, 244:439-446.

38. Andersson JO, Andersson SGE: Pseudogenes, junk DNA, and the dynamics of Rickettsia genomes. Mol Biol Evol 200 I, I 8:829-839.

39. Ortutay C, Gáspári Z, Tóth G, Jáger E, Vida G, Orosz L, Vellai T: Speciation in Chlamydia: genomewide phylogenetic analyses identified a reliable set of acquired genes. J Mol Evol 2003, 57:672-680.

40. Karunakaran KP, Rey-Ladino J, Stoynov N, Berg K, Shen C, Jiang X Gabel BR, Yu H, Foster LJ, Brunham RC: Immunoproteomic discovery of novel $\mathrm{T}$ cell antigens from the obligate intracellular pathogen Chlamydia. I Immunol 2008, I 80:2459-2465.

4I. Gieffers J, van Zandbergen G, Rupp J, Sayk F, Krüger S, Ehlers S, Solbach W, Maass M: Phagocytes transmit Chlamydia pneumoniae from the lungs to the vasculature. Eur Respir J 2004, 23:506-5 I 0.

42. Redecke V, Dalhoff K, Bohnet S, Braun J, Maass M: Interaction of Chlamydia pneumoniae and human alveolar macrophages: infection and inflammatory response. Am J Respir Cell Mol Biol 1998, 19:721-727

43. Rotoli BM, Dall'Asta V, Barilli A, D'lppolito R, Tipa A, Olivieri D, Gazzola GC, Bussolati O: Alveolar macrophages from normal subjects lack the NOS-related system y+ for arginine transport. Am J Respir Cell Mol Biol 2007, 37: I05-I I 2

44. van Zandbergen G, Gieffers J, Kothe H, Rupp J, Bollinger A, Aga E, Klinger M, Brade H, Dalhoff K, Maass M, et al.: Chlamydia pneumoniae multiply in neutrophil granulocytes and delay their spontaneous apoptosis. J Immunol 2004, I 72: I 768-I776.

45. Nakajo MN, Roblin PM, Hammerschlag MR, Smith P, Nowakowski M Chlamydicidal activity of human alveolar macrophages. Infect Immun 1990, 58:3640-3644.

46. Yong EC, Chi EY, Kuo C-C: Differential antimicrobial activity of human mononuclear phagocytes against the human biovars of Chlamydia trachomatis. J Immunol | 987, I39:| 297-I 302

47. Igietseme JU, Perry LL, Ananaba GA, Uriri IM, Ojior OO, Kumar SN Caldwell HD: Chlamydial infection in inducible nitric oxide synthase knockout mice. Infect Immun 1998, 66: I 282-I 286.

48. Fehlner-Gardiner C, Roshick C, Carlson JH, Hughes S, Belland RJ, Caldwell HD, McClarty G: Molecular basis defining human Chlamydia trachomatis tissue tropism. A possible role for tryptophan synthase. J Biol Chem 2002, 277:26893-26903.

49. Caldwell HD, Wood H, Crane D, Bailey R, Jones RB, Mabey D, Maclean I, Mohammed Z, Peeling R, Roshick C, et al.: Polymorphisms in Chlamydia trachomatis tryptophan synthase genes differentiate between genital and ocular isolates. J Clin Invest 2003, I I I: I757-1769.

50. Wood H, Caldwell HD, McClarty G: Tryptophan metablism in Chlamydiae. In Chlamydia: genomics and pathogenesis Edited by: Bavoil PM, Wyrick PB. Norfolk, UK: Horizon Bioscience; 2006:157-169.

51. Binet R, Maurelli AT: Frequency of spontaneous mutations that confer antibiotic resistance in Chlamydia spp. Antimicrob Agents Chemother 2005, 49:2865-2873.

52. Ekman MR, Grayston JT, Visakorpi R, Kleemola M, Kuo CC, Saikku P. An epidemic of infections due to Chlamydia pneumoniae in military conscripts. Clin Infect Dis 1993, I 7:420-425.

53. Larkin MA, Blackshields G, Brown NP, Chenna R, McGettigan PA McWilliam H, Valentin F, Wallace IM, Wilm A, Lopez R, et al.: Clustal W and Clustal $X$ version 2.0. Bioinformatics 2007, 23:2947-2948.

54. Guindon S, Gascuel O: A simple, fast, and accurate algorithm to estimate large phylogenies by maximum likelihood. Syst Biol 2003, 52:696-704.

55. Yang Z: PAML 4: Phylogenetic analysis by maximum likelihood. Mol Biol Evol 2007, 24:|586-I59|

56. Suyama M, Torrents D, Bork P: PAL2NAL: robust conversion of protein sequence alignments into the corresponding codon alignments. Nucleic Acids Res 2006, 34:W609-6I2

57. Zhang $\mathrm{Z}$, Li J, Zhao X-Q, Wang J, Wong GK-S, Yu J: KaKs_Calculator: Calculating $\mathrm{Ka}$ and $\mathrm{Ks}$ Through Model Selection and Model Averaging. Genomics Proteomics Bioinformatics 2006, 4(4):259-263. 